\title{
Effects of Land Use and Land Cover Change on Ecosystem Services in Ecological Preservation Development Districts of Beijing
}

\author{
Xiaona Liu, Hong Li*, Weiwei Zhang \\ Institute of System Comprehensive Development, Beijing Academy of Agriculture and Forest Science, Beijing 100097, \\ China
}

\begin{abstract}
Assessment the relationship between land use and land cover change (LUCC) and ecosystem service function gradually become a hot topic in both ecology and ecological economics fields. Based on remote sensing data of Landsat TM in 2005 and Landsat OLI in 2013, the effects of LUCC on ecosystem services in ecological preservation development districts (EPDD) of Beijing were analyzed from spatial and temporal perspectives. The results showed that: (1) Regional structure of land use and land cover in EPDD was forest land-farmland-orchard land; Forest land was the major land cover type, while farmland and orchard land dominated land use. From 2005 to 2013, changes in land use and land cover accelerated, and land use intensity was enhanced gradually with the land use degree comprehensive index $(\mathrm{La})$ varied from 229.67 to 233.09.The main characteristics of LUCC were farmland, grassland (decreasing) and construction land, forest land, water body, orchard land (increasing). (2) Between 2005 and 2013, ecosystem services value of EPDD showed a rising trend with the increments of $803.27 \times 10^{4}$ USD from $113535.19 \times 10^{4}$ USD to $114338.46 \times 10^{4}$ USD. Ecosystem services value of farmland, grassland, wetland and unused land decreased since 2005, while orchard land, forest land, water body increased. Service function value of food production, climate regulation and soil conservation decreased with climate regulation having the largest reduction; Service function value of raw materials production, gas regulation, hydrological regulation, waste treatment, biodiversity conservation and leisure entertainment increased, while hydrological regulation had the largest increment. Ecological environment and ecosystem service functions became more symphonious after EPDD foundation.
\end{abstract}

Keywords-land use and land cover change; ecosystem services; ecological preservation development district s (EPDD); Beijing.

\section{INTRODUCTION}

Land use and land cover change (LUCC) has the significant effects on regional climate, hydrology, biogeochemical cycles and biodiversity by changing the structure and function of ecosystem [1-2].The impacts of land use change on the function of ecosystem services gradually become a hot research in ecological economics and regional sustainable development fields[3-5]. With the process of urbanization, industrialization and agricultural modernization advancing, various ecosystems have been damaged more or less that resulted in ecosystem services gradually declining, which would threaten the sustainable development of human society seriously. The process of LUCC played a decisive role in maintaining the functions of ecosystem services. Therefore, it is significant for research on quantitative evaluation of ecosystem services functions and those changes induced by LUCC in different regional areas linking with versatile human activities [6].

Effects of land use and land cover change on ecosystem services in Beijing were studied from overall[7-9],regional [9]and basin scales[10], and had great achievements and progress in optimizing the evaluation system and application promotion. Yet, there are still many deficiencies for improvement, that is, inadequate focus on core ecological preservation regions, ignoring ecological value assessment of orchard land and construction land, insufficient calculation of equivalent value per unit area in the current year, and potential updating improvement of land use and land cover maps.

In order to promote optimization of total urban functions and economic and social development of the capital, four urban functional districts were designated officially in 2006, and ecological preservation development districts (EPDD) proposed firstly in 2005 according to the "Guidance on the County's Functional Orientation and Evaluation Indices Construction". Therefore, this study analyzed LUCC in EPDD of Beijing based on the interpretation of Landsat TM in 2005 and Landsat OLI in 2013 using decision tree method. Ecosystem services value was analyzed and compared based on the results of LUCC. The purpose of this study was to provide a scientific basis for quantitative analysis of effects of LUCC on ecological environment and reference for elaborating the ecosystem services in mountainous areas and achieve the coordination of economic and ecological benefits of sustainable development.

\section{MATERIALS AND METHODS}

\section{A. Study area}

EPDDare located in the northern and western part of Beijing mountainous areas, including Mentougou District, Pinggu District, Huairou District, Miyun County and Yanqing County. The complex topography with altitude ranging from $20 \mathrm{~m}$ to $2303 \mathrm{~m}$ formed the typical vertical climate change and significant vertical distribution of plant communities with warm temperate deciduous broad-leaved forest dominating. There are four large reservoirs, that is, 
Miyun reservoir in Miyuan County, Guanting reservoir in Yanqing County, Huairou reservoir in Huairou District, and Haizi reservoir in Pinggu District.The region cover 8746.65 $\mathrm{km}^{2}$ accounting for $53.30 \%$ of the total area of Beijingwith a population of 1.886 million in 2012 that has $61.51 \%$ of urbanization rate.Ecological preservation and leisure tourism functions are the two dominant features in EPDD, meanwhile the functions of urban industry, living and ecological agriculture [11].

\section{B. Land use and land cover classification system}

For the sake of comparing and analyzing the land use change and its effects on ecosystem servicesvalue since EPDD designation in 2005, land use and land cover classification maps were interpreted from Landsat TM in 2005 and Landsat OLI in 2013 using decision tree method (Fig.1). DEM with $30 \mathrm{~m}$ resolution and the topographic maps with the scale of 1:100000 were used to geometric rectification those two remote sensing images.

The system of land use and land cover has farmland, orchard land, forest land, grassland, water body, wetland, construction land and unused land based on the system of ecosystem types and the characteristics of land resources changes according to the existing research results of Costanza et al. [5]. The total classification accuracy of land use and land cover in 2005 and 2013 was $90.23 \%$ and 93.75\% after verifying with the higher images from Google Earth and SPOT5 in the relevant years, which can meet the demand of spatial-temporal analysis and practical application (Fig.1).

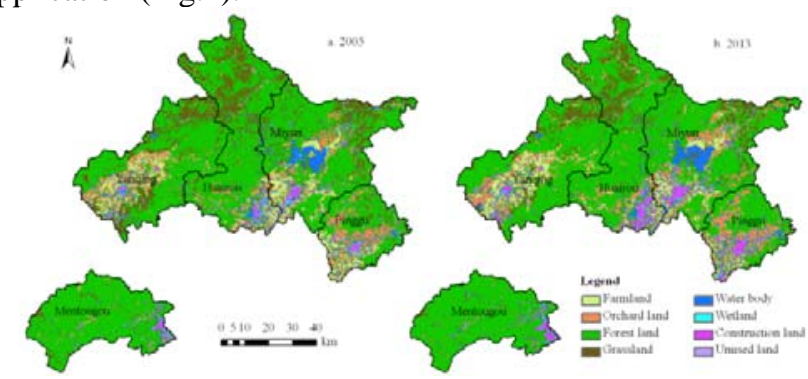

Figure 1. Land use and land cover maps of EPDD in 2005 and 2013

\section{Methodology}

The rate of land use change can reveal magnitude of different types of land use changes according to the index of the single land use dynamic degree $(K)$ [12]. Model is defined as:

$$
K=\frac{A_{i t_{2}}-A_{i t_{1}}}{A_{i t_{1}}} \times \frac{1}{t_{2}-t_{1}} \times 100 \%
$$

where $A_{i t 1}$ and $A_{i t 2}$ are the acreage of land type $i$ in the start and end of study period respectively. $U A_{i}$ is the acreage of land type $i$ with no transition. $t_{1}$ and $t_{2}$ refer to the start and end of study period. $t_{2}-t_{1}$ is the length of study period.

Land use intensity change reflects the human disturbance on land cover. Rating index of land use intensity is divided according to the land use intensity degree resulted from mankind. That is, unused land is 1 , forest land, grassland, water body and wetlandare 2, farmland and orchard land are 3 , and construction land is 4 [13]. The value range of the land use degree comprehensive index $(L a)$ is between 100 and 400 . The larger the value, the higher the land use intensity. The expression is as follows:

$$
L a=100 \times \sum_{i=1}^{n} A_{i} \times C_{i}
$$

where $A_{i}$ is the rating index of land use intensity of land typei. $C_{i}$ refers to land type $i$ as a percentage of the total area.

The principle and method of ecosystem service value assessment proposed by Costanza et al. [5]about the value of the world's ecosystem services and natural capital were mainly used in ecosystem service evaluation. The formula is as follows:

$$
E S V=\sum_{i}^{n} A_{i} \times V C_{i}
$$

WhereESV is the total value of ecosystem services(USD); $A_{i}$ is the acreage of land typei (ha); $V C_{i}$ refers to the ecosystem services of land typeiper unit area (USD $\left.h \mathrm{~h}^{-1} \cdot \mathrm{y}^{-1}\right)$

However, there have the problems of farmland underestimate and wetland overestimate towards China. Therefore, ecosystem services value unit area of Chinese terrestrial ecosystem were calculated and revised by the questionnaires from 200 ecologists in 2002 and 500 ecologists in 2007 [14-15]. Nine ecosystem service functions were selected, that were, food production (FP), raw materials production (RMP), gas regulation (GR),climate regulation (CR), hydrological regulation (HR), waste treatment (WT), soil conservation (SC), biodiversity conservation (BC) and leisure entertainment (LE) (Table 1). In light of the study period, this research adopted the research results in 2007, and the regional correction coefficient on ecosystem services value was 1.04 in Beijing [15]. One equivalent ecosystem services value per unit area in China was USD $54.84 \mathrm{ha}^{-1}$ in 2005 (USD 1= 8.19 CNY in 2005). Taken the actual situation of EPDD in account, the equivalent value per unit area of orchard land was calculated for its important role in Beijing mountainous economic and ecological resources. 
TABle I. Equivalent Ecosystem Services VAlue Per Unit AREA Of LAND Types IN BeiJing (USD HA ${ }^{-1} \mathrm{Y}^{-1}$ )

\begin{tabular}{cccccccc}
\hline Types & FL & GL & FD & OL & WL & WB & UL \\
\hline FP & 18.82 & 24.52 & 57.03 & 21.67 & 20.53 & 30.23 & 1.14 \\
RMP & 169.96 & 20.53 & 22.24 & 95.25 & 13.69 & 19.96 & 2.28 \\
GR & 246.38 & 85.55 & 41.06 & 165.97 & 137.45 & 29.09 & 3.42 \\
CR & 232.13 & 88.97 & 55.32 & 160.55 & 772.81 & 117.49 & 7.41 \\
HR & 233.27 & 86.69 & 43.92 & 159.98 & 766.53 & 1070.52 & 3.99 \\
WT & 98.10 & 75.28 & 79.28 & 86.69 & 821.28 & 846.95 & 14.83 \\
SC & 229.27 & 127.75 & 83.84 & 178.51 & 113.50 & 23.38 & 9.70 \\
BC & 257.22 & 106.65 & 58.17 & 181.94 & 210.45 & 195.62 & 22.81 \\
LE & 118.63 & 49.62 & 9.70 & 78.50 & 267.49 & 253.23 & 13.69 \\
\hline Total & 1603.78 & 665.56 & 450.56 & 1129.06 & 3123.73 & 2586.47 & 79.27 \\
\hline
\end{tabular}

Note: FD=farmland; $\mathrm{OL}=$ orchard land; FL=forest land; $\mathrm{GL}=$ grassland; $\mathrm{WB}=$ water body; $\mathrm{WL}=$ wetland;CL=construction land; $\mathrm{UL}=$ unused land.

\section{RESULTS AND ANALYSES}

\section{A. Analysis of land use and land cover changes}

Based on the land use and land cover maps in 2005 and 2013, land use intensity change was evaluated by the land use degree comprehensive index $(L a)$ to reflect the disturbance degree of human activities. The value of $L a$ in 2005 and 2013 were 229.67 and 233.09 with 3.42 increments, which indicated that land cover in EPDD was affected by human activities gradually with gentle range due to the ecological protection purpose in mountainous areas of Beijing. Regional structure of EPDD was forest land-farmland-orchard land with the sum proportion above 84\% (Table 2). Forest land was the dominant land cover type, while farmland and orchard land were the major land use types, which is consistent with the land use structural characteristics in mountainous areas of Beijing.

During 2005-2013, the acreage of all the land use types was changed with different amplitudes (Table 2). Farmland, grassland, wetland and unused land decreased, that was grassland experienced the largest area reduction of 24076.57 ha and wetland showed the fastest deceleration with the dynamic degree $(K)$ of -7.14 . Orchard land, forest land, water body, construction land increased, that was construction land had the largest area increment of 15529.66 ha and water body showed the fastest growth with the dynamic degree $(K)$ of 5.22. Linked with land use intensity change, human activities of EPDD designation, economic development, urbanization and agricultural restructuring are the main causes of land use and land cover change in EPDD.

Table II. Area Change And Dynamic Degree Of LANd Use Type IN EPDD

\begin{tabular}{|c|c|c|c|c|c|c|}
\hline \multirow{2}{*}{$\begin{array}{l}\text { Land } \\
\text { type }\end{array}$} & \multicolumn{2}{|c|}{ Area(ha) } & \multicolumn{2}{|c|}{ Proportion(\%) } & \multirow{2}{*}{$\begin{array}{l}\text { Increments } \\
\text { (ha) }\end{array}$} & \multirow{2}{*}{$K(\%)$} \\
\hline & 2005 & 2013 & 2005 & 2013 & & \\
\hline FD & 93797.34 & 86602.16 & 10.73 & 9.90 & -7195.18 & -0.96 \\
\hline $\mathrm{OL}$ & 78554.43 & 83086.39 & 8.98 & 9.50 & 4531.96 & 0.72 \\
\hline FL & 562434.65 & 572048.82 & 64.30 & 65.40 & 9614.17 & 0.21 \\
\hline GL & 70227.69 & 46151.12 & 8.03 & 5.28 & -24076.57 & -4.29 \\
\hline WB & 15052.00 & 21340.14 & 1.72 & 2.44 & 6288.14 & 5.22 \\
\hline WL & 5249.26 & 2250.67 & 0.60 & 0.26 & -2998.58 & -7.14 \\
\hline UL & 45477.59 & 61007.25 & 5.20 & 6.97 & 15529.66 & 4.27 \\
\hline FD & 3872.04 & 2178.45 & 0.44 & 0.25 & -1693.59 & -5.47 \\
\hline
\end{tabular}

Note: $\mathrm{FD}=$ farmland; $\mathrm{OL}=$ orchard land; $\mathrm{FL}=$ forest land; $\mathrm{GL}=$ grassland; $\mathrm{WB}=$ water body; $\mathrm{WL}=$ wetland; $\mathrm{CL}=$ construction land; $\mathrm{UL}=$ unused land.

\section{B. Analysis of ecosystem service value changes}

Based on the equivalent ecosystem services value per unit area of land use type in Beijing (Table 1), changes of ecosystem services value in EPDD from 2005 to 2013 were analyzed from total and single service function value perspectives (Table 3 and Table 4).Between 2005 and 2013, the ecosystem services value of EPDD showed a rising trend with the increments of $803.27 \times 10^{4}$ USD from $113535.19 \times 10^{4}$ USD to $114338.46 \times 10^{4}$ USD and $0.71 \%$ value change rate. The ecosystem services value of farmland, grassland, wetland and unused land decreased after the EPDD established, while orchard land, forest land, water body increased. Obviously, the ecosystem services value of water body experienced the largest increment of $1626.41 \times 10^{4}$ USD, followed by forest land of $1541.90 \times 10^{4}$ USD and orchard land of $511.69 \times 10^{4}$ USD. Meanwhile, the ecosystem services value of grassland had the highest reduction of $1602.44 \times 10^{4} \mathrm{USD}$, and unused land had the lowest reduction of $13.43 \times 10^{4}$ USD. Although most of land use types transferred into construction land may result in the decline of the total ecosystem value of EPDD, orchard land, forest land and water body were converted from other 
land types with small ecological value per unit. Therefore,

became more symphonious after EPDD designated.

the ecological environment and ecosystem service functions

TABLE III. ECOSYSTEM SERVICES VALUE CHANGES IN EPDD

\begin{tabular}{|c|c|c|c|c|c|}
\hline \multirow[t]{2}{*}{ Land type } & \multirow{2}{*}{$\begin{array}{c}V C i \\
(\mathrm{USD} \\
\left.\mathrm{ha}^{-1} \mathrm{y}^{-1}\right)\end{array}$} & \multicolumn{2}{|c|}{$E S V\left(10^{4} \mathrm{USD}\right)$} & \multirow{2}{*}{$\begin{array}{l}\text { Change of ESV } \\
\left(10^{4} \text { USD }\right)\end{array}$} & \multirow[t]{2}{*}{ Change rate of $E S V(\%)$} \\
\hline & & 2005 & 2013 & & \\
\hline FD & 450.56 & 4226.13 & 3901.95 & -324.19 & -7.67 \\
\hline OL & 1129.06 & 8869.27 & 9380.95 & 511.69 & 5.77 \\
\hline FL & 1603.78 & 90202.14 & 91744.05 & 1541.90 & 1.71 \\
\hline GL & 665.56 & 4674.07 & 3071.63 & -1602.44 & -34.28 \\
\hline WB & 2586.47 & 3893.15 & 5519.56 & 1626.41 & 41.78 \\
\hline WL & 3123.73 & 1639.73 & 703.05 & -936.68 & -57.12 \\
\hline UL & 79.27 & 30.69 & 17.27 & -13.43 & -43.74 \\
\hline Total & 9638.43 & 113535.19 & 114338.46 & 803.27 & 0.71 \\
\hline
\end{tabular}

Note: FD=farmland; $\mathrm{OL}=$ orchard land; $\mathrm{FL}=$ forest land; $\mathrm{GL}=$ grassland; $\mathrm{WB}=$ water body; $\mathrm{WL}=$ wetland; $\mathrm{CL}=\mathrm{construction}$ land; $\mathrm{UL}=$ unused land.

TABLE IV. SINGLE ECOSYSTEM SERVICE FUNCTION VALUE CHANGES IN EPDD

\begin{tabular}{|c|c|c|c|c|c|c|c|}
\hline \multirow[b]{2}{*}{ Types } & \multicolumn{3}{|c|}{2005} & \multicolumn{3}{|c|}{2013} & \multirow{2}{*}{$\begin{array}{c}2005-1013 \\
\text { Changes of ESV } \\
\left(10^{4} \text { USD }\right)\end{array}$} \\
\hline & $\begin{array}{c}E S V \\
\left(10^{4} \mathrm{USD}\right) \\
\end{array}$ & P (\%) & $\mathrm{S}$ & $\begin{array}{c}E S V \\
\left(10^{4} \mathrm{USD}\right)\end{array}$ & $\mathrm{P}(\%)$ & $\mathrm{S}$ & \\
\hline FD & 1992.57 & 1.76 & 9 & 1933.08 & 1.69 & 9 & -59.50 \\
\hline RMP & 10698.27 & 9.42 & 6 & 10847.46 & 9.49 & 6 & 149.20 \\
\hline GR & 16264.22 & 14.33 & 3 & 16317.29 & 14.27 & 3 & 53.07 \\
\hline CR & 16046.07 & 14.13 & 5 & 15928.88 & 13.93 & 5 & -117.19 \\
\hline HR & 17412.65 & 15.34 & 2 & 17911.73 & 15.67 & 1 & 499.08 \\
\hline WT & 9182.45 & 8.09 & 7 & 9361.56 & 8.19 & 7 & 179.10 \\
\hline SC & 16079.30 & 14.16 & 4 & 15991.74 & 13.99 & 4 & -87.55 \\
\hline BC & 17604.51 & 15.51 & 1 & 17691.67 & 15.47 & 2 & 87.16 \\
\hline LE & 8255.14 & 7.27 & 8 & 8355.03 & 7.31 & 8 & 99.89 \\
\hline Total & 113535.19 & 100 & & 114338.40 & 100 & & 803.27 \\
\hline
\end{tabular}

Note: $\mathrm{P}=$ proportion; $\mathrm{S}=$ sort.

Analysis of single service function value changes of ecosystem in EPDD from 2005 to 2013 (Table 4) could find both the dominant and lacking single service function in study region. In 2005, the service function value of biodiversity conservation covered the largest proportion of $15.51 \%$ following by hydrological regulationof $15.34 \%$, and food production the lowest proportion of $1.76 \%$. In 2013, the service function of hydrological regulation exceeded that of biodiversity conservation. During the period of 2005-2013, the service function value of food production, climate regulation and soil conservation decreased, and the service function value of climate regulation had the largest reduction of $117.19 \times 10^{4} \mathrm{USD}$, which were caused from the area reduction of forest land, grassland and farmland and area increments of orchard land and construction land which were influenced by human activities. Additionally, the service function value of raw materials production, gas regulation, hydrological regulation, waste treatment, biodiversity conservation and leisure entertainment increased, while hydrological regulation had the largest increment of $499.08 \times 10^{4}$ USD and gas regulation the smallest of $53.07 \times 10^{4}$ USD. The conclusion of single service function value evaluation coincided with the primary purpose and features of EPDD.

\section{CONCLUSIONS AND DISCUSSION}

The foundation of EPDD is a priority to ensure the ecological construction and water conservation in Beijing. Based on the land use and land cover maps extracting from Landsat TM and OLI in 2005 and 2013, spatial-temporal change analysis of land use and land cover, ecosystem services and effects of LUCC on ecosystem services in EPDD of Beijing were conducted comprehensively. The results showed that:

(1) Regional structure of land use and land cover in EPDD was forest land-farmland-orchard land. Forest land 
was the dominant land cover type in EPDD, while farmland and orchard land were the major land use types. Changes in land use and land cover accelerated. Land use intensity caused by human activities was enhanced gradually with the land use degree comprehensive index $(L a)$ changed from 229.67 to 233.09 from 2005 to 2013. Farmland, grassland, wetland and unused land decreased, while orchard land, forest land, water body, construction land increased; Wetland and water body showed the fastest deceleration and growth respectively. Human activities of EPDD designation, economic development, urbanization and agricultural restructuring are the main causes of land use and land cover change in EPDD.

(2) Between 2005 and 2013, ecosystem services value of EPDD showed a rising trend with the increments of $803.27 \times 10^{4} \quad$ USD from $113535.19 \times 10^{4}$ USD to $114338.46 \times 10^{4}$ USD. The ecosystem services value of farmland, grassland, wetland and unused land decreased after the EPDD established, while orchard land, forest land, water body increased. The leading single function changed from biodiversity conservation (15.51\%) in 2005 to hydrological regulation (15.67\%) in 2013, and food production function value had the lowest proportion. During 2005-2013, the service function value of food production, climate regulation and soil conservation decreased, and the service function value of climate regulation had the largest reduction; the service function value of raw materials production, gas regulation, hydrological regulation, waste treatment, biodiversity conservation and leisure entertainment increased, while hydrological regulation had the largest increments.

Assessment of ecosystem services value changes under LUCC is beneficial to guide regional sustainable development and achieve ecological and economic integration and development. According to the actual situation in EPDD of Beijing, ecosystem services value assessment of orchard land is more practical and operable. At the same time, ecosystem services value of construction land should be considered through field survey and related-data acquisition. However, land use and land cover classification method and accuracy should be improved for further study and yield survey validation using more multi-source data and multiple classifiers. More studies on the driving forces of land use change should be strengthened, especially the ecological land and agricultural land. Thus, the integral and practical assessment system of ecosystem services based on LUCC could be reliable foundation for references to sustainable development and ecological construction.

\section{V.ACKNOWLEDGEMENTS}

The research work was supported by Beijing Municipal Science \& Technology Plan Project under Grant No. D131100000613002.

\section{REFERENCES}

[1] Turner II B L, Skole D, Sanderson S, et al. Land use and land cover change. Stockholm: IGBP Report No. 35 and IHDP Report No. 7. 1995

[2] Li Y S, Zhou G J, Liang T, et al. Study of land use change on the gains and losses of ecosystem service function values of Chaohu Lake Basin. Geographical Research, 28(6), pp. 1656-1664, 2009.

[3] Nelson E, Sander H, Hawthorne P, et al. Projecting global land-use change and its effect on ecosystem service provision and biodiversity with simple models. Plos One, 5(12), pp. e14327, 2010.

[4] Costanza R, de Groot R, Sutton P, et al. Changes in the global value of ecosystem services. Global Environmental Change, 26, pp. 152-158, 2014.

[5] Costanza R, D'Arge R, de Groot R, et al. The value of the world's ecosystem services and natural capital.Nature, 387(6630), pp. 253-260, 1997.

[6] Xie G D, Lu C X, Cheng S K. Progress in evaluation the global ecosystem services. Resources Science, 23(6), pp. 5-9, 2001.

[7] Shen H J, Guo R Z, Jiang Y M, et al. Effects of land use change on ecosystem services value based on RS and GIS technology. Journal of Anhui Agricultural Science, 36(11), pp. 4781-4783, 2008.

[8] Wan L, Chen Y Q, Tan J, et al. Variation of ecosystem services value in the suburbs of Beijing based on the land use change. Areal Research and Development, 28(4), pp. 94-99, 109, 2009.

[9] Tang X M, Chen B M, Lu Q B. Comprehensive evaluation of land use ecosystem service value in Beijing. Acta Scientiarum Naturalium Universitatis Pekinensis, 47(5), pp. 853-862, 2011.

[10] Li Y F, Luo Y C, Liu G, et al. Effects of land use change on ecosystem services: a case study in Miyun reservoir watershed. ActaEcologicaSinica, 33(3), pp. 726-736, 2013.

[11]Zhang L. Beijing mountain functional zoning and relative polices. Economic Geography, 29(6), pp. 989-994, 2009.

[12] Wang X L, Bao Y H. Study on the methods of land use dynamic change research. Progress in Geography, 18(1), pp. 81-87, 1999.

[13] Deng R. Construction and protection of ecological environment in Xishuangbanna district. Yunnan Environmental Science, 23(S1), pp. 133-134, 2004.

[14] Xie G D, Lu C X, Leng Y F, et al. Ecological assets valuation of the Tibetan Plateau. Journal of Natural Resources, 18(2), pp. 189-196, 2003.

[15] Xie G D, Zhen L, Lu C X, et al. Expert knowledge based valuation method of ecosystem services in China. Journal of Natural Resources, 23(5), pp. 911-919, 2008 